\title{
Pengaruh Green Product, Servicescape dan Kualitas Layanan terhadap Kepuasan Konsumen pada Resto Berbasis Alam
}

\author{
Richardus Bowo Harcahyo $^{1}$; Sentot Suciarto Athanasius $^{2}$; Veronica Kusdiartini ${ }^{3}$ \\ 'bow@unika.ac.id; ${ }^{2}$ sentot.sa@unika.ac.id; ${ }^{3}$ vero@unika.ac.id \\ Universitas Katolik Soegijapranata Semarang
}

\begin{abstract}
Restaurant consumers will choose and visit a restaurant if they are satisfied, well served and get what they need at the restaurant. The problem of this research is how the influence of service quality, green product and servicescape on consumer satisfaction. The purpose of this study was to determine the effect of green product, servicescape and service quality on consumer satisfaction at the Surrounding NatureBased Restaurant. The restaurant's efforts in maintaining customer satisfaction are inseparable from the quality of service provided by the restaurant. In addition, consumers who visit restaurants not only enjoy culinary delights, but also enjoy the servicescape or the natural scenery around the restaurant. Kampoeng Rawa restaurant in Ambarawa is a restaurant in the middle of a stretch of rice fields and just into the middle of Rawapening swamp area and is above the water. The view in the middle of the swamp and water makes the restaurant atmosphere attractive for visitors. This research was a consumer survey of Kampoeng Rawa restaurant visitors who enjoy culinary and the nature around the restaurant. Based on quota accidental sampling, 60 consumer respondents were determined who dine in at the Kampoeng Rawa restaurant during March 2021. The results showed that there was a positive and significant effect of service quality and servicescape variables on restaurant customer satisfaction. Green products do not have a significant effect. Furthermore, sustainable restaurant service management will have an impact on its contribution to the economy of private owners, BUMDES owners and the surrounding community who are employees. A restaurant that is managed by paying attention to the quality of service and an attractive surrounding atmosphere can lead to satisfaction for restaurant consumers.
\end{abstract}

Keywords : service quality; green product; service scape; satisfaction.

\section{PENDAHULUAN}

Pengertian restoran atau resto adalah suatu usaha yang menyediakan jasa pelayanan makanan dan minuman yang dikelola secara komersial. Banyak dibangun resto berbasis alam sekitar misalnya resto dengan tempat pemancingan (Semarang Island Resto, Prima Raja, Pemancingan Barokah), resto dengan pemandangan alam sekitar (Kampoeng Kopi Banaran, Eling Bening, Gubug Makan Mang Engking, Eva Coffee House) dan lainnya. Resto dengan memanfaatkan panorama lingkungan sekitar menjadi usaha yang banyak diminati di kabupaten 
JEMAP: Jurnal Ekonomi, Manajemen, Akuntansi, dan Perpajakan

ISSN: 2622-612X (Media Online) | Vol.4 | No.2 | Oktober 2021

Semarang. Restoran atau rumah makan ini bisa ada di pinggir jalan Semarang Solo, di pinggir jalur lingkar kota Ambawara, di kawasan wisata Bandungan dan di sekitar tempat-tempat wisata lainnya di Kabupaten Semarang. Salah satu resto yang memanfaatkan lingkungan sekitar adalah Resto Apung Kampoeng Rawa di Ambarawa.

Setiap usaha resto memerlukan upaya agar konsumen tertarik mendatangi resto tersebut dengan membuat lingkungan sekitar resto yang menarik atau konsumen melihat service scape dari resto tersebut. Upaya menarik perhatian dengan service scape dilakukan oleh restoran agar dikunjungi konsumen. Upaya ini dicoba dilakukan Kampoeng Rawa dengan membuat kekhasan yaitu resto apung yaitu restoran yang mengapung di atas air rawa di Rawapening. Hamparan sawah menghijau dan pemandangan gunung di kejauhan turut mendukung resto ini. Oleh karena itu kondisi sekitar ini disebut service scape atau lingkungan jasa. Zeithaml melihat lingkungan jasa atau service scape menjadi salah satu daya tarik bagi konsumen/pengunjung. (Zeithaml, 1985).

Perumusan masalah dalam penelitian ini secara simultan adalah : Apakah green product, service scape dan kualitas layanan berpengaruh terhadap kepuasan konsumen pada Resto Kampoeng Rawa yang Berbasis Alam Sekitar di Kabupaten Semarang ? Sedangkan secara parsial akan diteliti masalah:

a. Bagaimanakah pengaruh green product terhadap kepuasan konsumen Resto Kampoeng Rawa?

b. Bagaimanakah pengaruh service scape terhadap kepuasan konsumen Resto Kampoeng Rawa?

c. Bagaimanakah pengaruh kualitas layanan terhadap kepuasan konsumen Resto Kampoeng Rawa?

\section{TINJAUAN PUSTAKA}

\section{Lingkungan dan Pengelolaan Lingkungan Resto}

Otto Soemarno, seorang pakar lingkungan mendefinisikan lingkungan hidup sebagai jumlah semua benda dan kondisi yang ada dalam ruang yang kita tempati yang mempengaruhi kehidupan kita. (Huasein, 1993).Lingkungan adalah keadaan 
JEMAP: Jurnal Ekonomi, Manajemen, Akuntansi, dan Perpajakan

ISSN: 2622-612X (Media Online) | Vol.4 | No.2 | Oktober 2021

sekitar yang mempengaruhi perkembangan dan tingkah laku makhluk hidup (Kamus Besar Bahasa Indonesia, 2005).Lingkungan hidup dapat didefinisikan sebagai: 1) daerah tempat suatu makhluk hidup berada; 2) keadaan atau kondisi yang melingkupi suatu makhluk hidup; 3) keseluruhan keadaan yang meliputi suatu makhluk hidup atau sekumpulan makhluk hidup. (Supardi, 2009).

\section{Pengertian dan Kriteria Green Product}

Kasali (2005) memberikan definisi dari produk hijau (green product) sebagai ilustrasi dari barang atau produk yang dihasilkan oleh produsen yang terkait dengan rasa aman dan tidak menimbulkan dampak bagi kesehatan manusia serta tidak berpotensi merusak lingkungan hidup. Di samping itu, produk bersih juga dikaitkan dengan penggunaan bahan baku yang senantiasa memperhatikan generasi mendatang, produk bersih juga bertujuan untuk mengurangi sampah (waste) baik dari prosesnya maupun dari daur hidup produk tersebut. Lebih jauh, Nugrahadi (2002) menyatakan bahwa produk bersih (green produk) selalu berorientasi pada lingkungan.

Menurut Ottman (1998:89) menyatakan bahwa produk hijau secara prinsip dapat bertahan dalam periode waktu yang cukup lama, tidak mengandung racun, terbuat dari bahan yang bersahabat dengan lingkungan dan dapat didaur ulang, atau dikemas secara sederhana (simple) dan minimalis. Green product tersebut dibuat, disebarluaskan, dan digunakan untuk mengurangi dampak negatif terhadap lingkungan seperti kerusakan dan pencemaran pada lingkungan.Green product atau produk ramah lingkungan menurut Handayani (2012), merupakan suatu produk yang dirancang dan diproses dengan suatu cara untuk mengurangi efek-efek yang dapat mencemari lingkungan, baik dalam produksi, pendistribusian, dan pengonsumsinya. Menurut Rath (2013), green product didefinisikan sebagai produk-produk industri yang diproduksi melalui teknologi ramah lingkungan dan tidak menyebabkan bahaya terhadap 24 lingkungan. D'Souza et al., (2006) menjelaskan bahwa green product adalah produk yang memiliki manfaat bagi konsumen dan juga memiliki manfaat sosial yang dirasakan oleh konsumen, seperti ramah terhadap lingkungan. 
JEMAP: Jurnal Ekonomi, Manajemen, Akuntansi, dan Perpajakan

ISSN: 2622-612X (Media Online) | Vol.4 | No.2 | Oktober 2021

\section{Konsep Service Scape}

Service scape atau lingkungan jasa adalah lingkungan fisik dimana layanan jasa terjadi dan bagaimana lingkungan fisik ini mempengaruhi kinerja karyawan dan konsumen (Chase, 2002: 192; Bitner, 1992). Bitner membagi 3 dimensi servicescape yaitu ambient condition, spacial layout and functionality, dan sign, symbols and artifacts. Penelitian Parish, Berry dan Lam (2008) melihat service scape dalam kegiatan pekerja meliputi kenyamanan (convenience), keamanan (safety) dan menyenangkan (pleasantness). Di dalam resto, ada penggunaan tongtong penopang bangunan resto sehingga konsumen merasa ada sedikit ayunan yang menyenangkan ketika menikmati kuliner resto. Indikator service scape penelitian adalah kondisi sekitar resto (pemandangan alam sekitar resto), ruang/fungsi (pondok-pondok makan dan bangunan resto) dan tanda-simbol-artifak yang digunakan resto seperti hiasan patung dan lainnya, meja kasir, meja layanan.

\section{Konsep Kualitas Layanan}

Kualitas layanan (kualitas jasa) merupakan persepsi konsumen terhadap proses produksi jasa. Menurut Zeithaml dkk (1985), ada lima (5) dimensi kualitas layanan yaitu disingkat TERRA- tangible, empathy, reliability, responsiveness dan assurance (Kotler dan Keller, 2012: 396). Tangible merupakan wujud fisik atau penampilan fasilitas fisik (peralatan makan piring sendok resto, seragam karyawan, kelengkapan peralatan makanan). Emphaty merupakan kepedulian atau perhatian karyawan terhadap konsumen. Realibility atau keandalan adalah kemampuan memberikan jasa yang penyelesaiannya akurat dan sesuai dengan pesanan konsumen. Responsiveness atau daya tanggap merupakan kecepatan layanan, kecepatan menanggapi pertanyaan atau permintaan konsumen. Assurance atau kepastian adalah pelayanan dengan sopan santun karyawan sehingga menimbulkan keyakinan dan kepercayaan.(Sasongko dan Subagio, 2013).

\section{Konsep Kepuasan Konsumen}

Upaya pemasaran menurut Kotler adalah upaya pemenuhan kebutuhan dan kepuasan konsumen. Kepuasan adalah perasaan seseorang atas kesenangan atau kekecewaan karena membandingkan kinerja dan harapan (Kotler dan Keller, 20112: 150). Kepuasan pelanggan adalah terpenuhinya kebutuhan pelanggan. Apa 
JEMAP: Jurnal Ekonomi, Manajemen, Akuntansi, dan Perpajakan

yang dirasakan pelanggan atas layanan yang diberikan dibandingkan dengan apa yang diharapkan. Hal ini juga sesuai dengan pandangan Schiffman dan Kanuk bahwa kepuasan pelanggan merupakan persepsi individu terhadap performans produk atau jasa terkait dengan harapannya (Schiffman dan Kanuk, 2007: 9). Indikator variabel kepuasan konsumen ini adalah tidak adanya keluhan atau keluhan teratasi, perasaan puas pelanggan pada keseluruhan produk resto, kesesuaian dengan ekspektasi/harapan pelanggan dan melakukan pembelian ulang.

\section{Penelitian Terdahulu}

\section{Tabel 1. Penelitian terdahulu}

\begin{tabular}{|c|c|c|c|c|}
\hline No & $\begin{array}{l}\text { Judul, Nama Peneliti, } \\
\text { dan Tahun Literatur }\end{array}$ & $\begin{array}{l}\text { Variabel } \\
\text { Penelitian }\end{array}$ & Alat Analisis & Hasil Penelitian \\
\hline 1. & $\begin{array}{l}\text { Pengaruh kualitas } \\
\text { produk, harga dan } \\
\text { servicescape terhadap } \\
\text { kepuasan konsumen } \\
\text { pengguna rumah } \\
\text { makan Ocean } 27 \\
\text { Manado } \\
\text { (Ransulangi et al, } \\
\text { 2015) }\end{array}$ & $\begin{array}{l}\text { Kualitas produk, } \\
\text { harga, service } \\
\text { scape, kepuasan } \\
\text { konsumen }\end{array}$ & $\begin{array}{l}\text { Regresi linier } \\
\text { berganda }\end{array}$ & $\begin{array}{l}\text { Ada pengaruh signifkan } \\
\text { kualitas produk dan } \\
\text { service scape. Harga } \\
\text { tidak signifikan } \\
\text { pengaruhnya. }\end{array}$ \\
\hline 2. & $\begin{array}{l}\text { Faktor-Faktor yang } \\
\text { Mempengaruhi } \\
\text { Keputusan Pembelian } \\
\text { Green Product } \\
\text { (Aziah Fatmawati, } \\
\text { 2015) }\end{array}$ & $\begin{array}{l}\text { Budaya, Sosial, } \\
\text { Pribadi, } \\
\text { Psikologi, } \\
\text { Produk, Harga, } \\
\text { Tempat, } \\
\text { Promosi }\end{array}$ & $\begin{array}{l}\text { Regresi Linier } \\
\text { Berganda }\end{array}$ & $\begin{array}{l}\text { Variabel budaya, sosial, } \\
\text { psikologi, harga, } \\
\text { tempat, promosi secara } \\
\text { parsial berpengaruh } \\
\text { signifikan terhadap } \\
\text { keputusan pembelian } \\
\text { sedangkan variabel } \\
\text { pribadi dan produk } \\
\text { tidak berpengaruh } \\
\text { signifikan terhadap } \\
\text { keputusan pembelian }\end{array}$ \\
\hline 3. & $\begin{array}{l}\text { Pengaruh Service } \\
\text { scape terhadap } \\
\text { Customer Loyalty } \\
\text { Restoran McDonald's } \\
\text { Surabaya } \\
\text { (Rizky Ardi } \\
\text { Purnama, dan Erna } \\
\text { Andajani, 2019) }\end{array}$ & $\begin{array}{l}\text { Service Scape, } \\
\text { Emotion, } \\
\text { Satisfaction, } \\
\text { Loyalty }\end{array}$ & $\begin{array}{l}\text { Uji Goodness } \\
\text { of Fit dengan } \\
\text { AMOS }\end{array}$ & $\begin{array}{l}\text { Terdapat pengaruh } \\
\text { positif dan signifikan } \\
\text { service scape terhadap } \\
\text { emotion, emotion } \\
\text { terhadap satisfaction, } \\
\text { dan pengaruh } \\
\text { satisfaction terhadap } \\
\text { loyalty. }\end{array}$ \\
\hline 4. & $\begin{array}{l}\text { The Effect of Service } \\
\text { scape on Service } \\
\text { Workers } \\
\text { (Janet T Parish, } \\
\text { Leonard L Berry \& } \\
\text { Shun Y Lam, 2013) }\end{array}$ & $\begin{array}{l}\text { Service scape, } \\
\text { Job Satisfaction, } \\
\text { Committment }\end{array}$ & SEM Analysis & $\begin{array}{l}\text { Model terdukung oleh } \\
\text { analisis. }\end{array}$ \\
\hline
\end{tabular}


JEMAP: Jurnal Ekonomi, Manajemen, Akuntansi, dan Perpajakan

\begin{tabular}{|c|l|l|l|l|}
\hline No & $\begin{array}{l}\text { Judul, Nama Peneliti, } \\
\text { dan Tahun Literatur }\end{array}$ & $\begin{array}{c}\text { Variabel } \\
\text { Penelitian }\end{array}$ & Alat Analisis & Hasil Penelitian \\
\hline 5. & $\begin{array}{l}\text { Strategi promosi, } \\
\text { Kualitas Produk dan } \\
\text { Kualitas layanan } \\
\text { terhadap Kepuasan } \\
\text { Pelanggan } \\
\text { McDonald's Manado } \\
\text { (Resti Avita } \\
\text { Haryanto, 2013) }\end{array}$ & $\begin{array}{l}\text { Strategi } \\
\text { Promosi, } \\
\text { Kualitas } \\
\text { Produk, } \\
\text { Kualitas } \\
\text { Layanan, } \\
\text { Kepuasan } \\
\text { Pelanggan }\end{array}$ & $\begin{array}{l}\text { Regresi } \\
\text { Berganda }\end{array}$ & $\begin{array}{l}\text { Ada pengaruh secara } \\
\text { bersama. Kualitas } \\
\text { layanan secara } \\
\text { signifikan berpengaruh } \\
\text { terhadap kepuasan. }\end{array}$ \\
\hline 6. & $\begin{array}{l}\text { Pengaruh kualitas } \\
\text { layanan terhadap } \\
\text { kepuasan pelanggan } \\
\text { ayam penyet ria } \\
\text { (Felita Sasongko dan } \\
\text { Hartono Subagio, } \\
\text { 2013) }\end{array}$ & $\begin{array}{l}\text { Kualitas } \\
\text { layanan, } \\
\text { kepuasan } \\
\text { pelanggan }\end{array}$ & $\begin{array}{l}\text { Regresi } \\
\text { Berganda }\end{array}$ & $\begin{array}{l}\text { Ada pengaruh kualitas } \\
\text { layanan (TERRA) } \\
\text { terhadap kepuasan } \\
\text { pelanggan. } \\
\text { Responsiveness dan } \\
\text { Assurance mempunyai } \\
\text { pengaruh yang lebih } \\
\text { besar dibanding dimensi } \\
\text { yang lain. }\end{array}$ \\
\hline
\end{tabular}

\section{Kerangka Pikir Penelitian}

Dalam penelitian ini akan dilihat pengaruh beberapa variabel terhadap kepuasan konsumen Resto Kampoeng Rawa di Ambarawa. Konsumen berkunjung ke lokasi resto tidak hanya untuk tujuan kuliner saja melainkan juga untuk menikmati pemandangan sekitar resto yang menarik. Ada hamparan sawah menghijau, ada wisata air sekitar rawa pening dan ada arena permainan anak-anak. Adanya beberapa sarana di sekitar resto menjadikan peneliti ingin mengetahui apakah ada pengaruhnya terhadap konsumen selain kuliner yang ditawarkan dan kualitas layanannya.

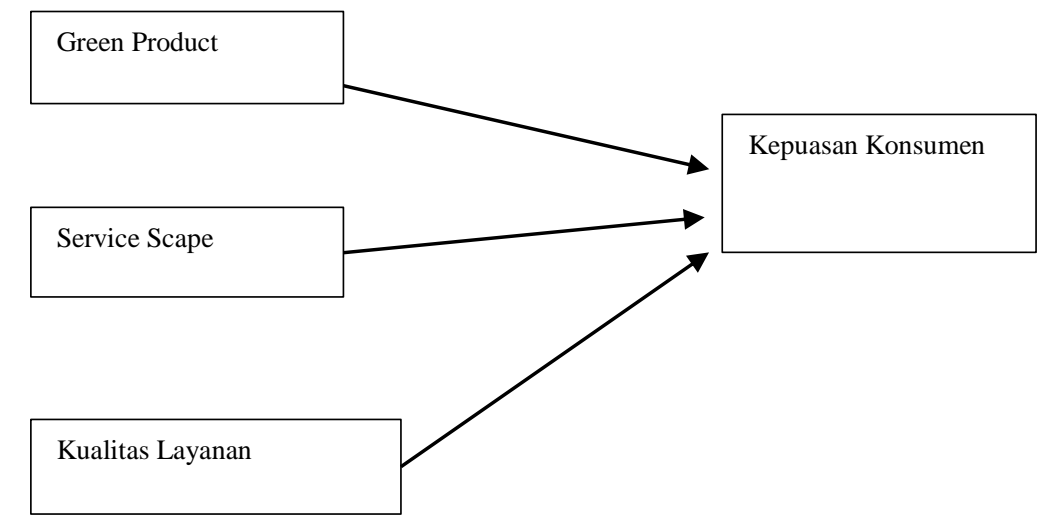

Gambar 1. Diagram Kerangka Pikir Penelitian 
JEMAP: Jurnal Ekonomi, Manajemen, Akuntansi, dan Perpajakan

Dengan demikian beberapa hipotesis yang diajukan dalam penelitian ini adalah:

H1. Diduga kualitas layanan berpengaruh positif dan signifikan terhadap kepuasan konsumen Restoran Kampoeng Rawa Ambarawa.

H2. Diduga servicescape berpengaruh positif dan signifikan terhadap kepuasan konsumen Restoran Kampoeng Rawa Ambarawa.

H3. Diduga green product berpengaruh positif dan signifikan terhadap kepuasan konsumen Restoran Kampoeng Rawa Ambarawa.

H4. Diduga secara bersama-sama variabel kualitas layanan, servicescape, dan green product berpengaruh signifikan terhadap kepuasan konsumen Restoran Kampoeng Rawa Ambarawa.

\section{Definisi Operasional Variabel}

Tabel 2. Definisi Operasional dan Indikator Variabel

\begin{tabular}{|c|c|c|}
\hline Nama Variabel & Definisi & Indikator \\
\hline Kualitas Layanan & $\begin{array}{l}\text { Penilaian konsumen terhadap } \\
\text { proses penyediaan produk dan } \\
\text { jasa makanan dengan } \\
\text { indikator tangibles, emphaty, } \\
\text { reliability, responsiveness, } \\
\text { assurance }\end{array}$ & $\begin{array}{ll}\text { - } & \text { Tangibles = wujud fisik layanan } \\
\text { yang diterima konsumen } \\
\text { - } & \text { Emphaty = kepedulian dan perhatian } \\
\text { kepada konsumen } \\
\text { - } \quad \text { Responsiveness = kecepatan dan } \\
\text { tanggap } \\
\text { - } \quad \text { Reliability = handal dan akurat } \\
\text { dalam pemenuhan janji dan layanan } \\
\text { - } & \text { Assurance = keamanan dan jaminan } \\
& \text { terlayaninya konsumen dengan baik }\end{array}$ \\
\hline Service scape & $\begin{array}{l}\text { Lingkungan sekitar layanan } \\
\text { resto yang nyaman, aman dan } \\
\text { menyenangkan konsumen }\end{array}$ & 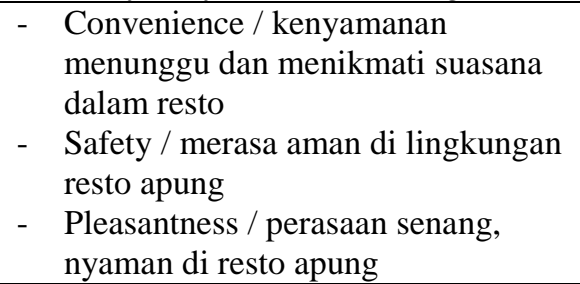 \\
\hline Green Product & $\begin{array}{l}\text { Aktifitas menyediakan barang } \\
\text { dan jasa yang mengurangi } \\
\text { dampak negatif pada } \\
\text { lingkungan misal } \\
\text { menggunakan bahan segar } \\
\text { dari lingkungan, menjaga } \\
\text { udara, menghemat energi dan } \\
\text { menghemat air. }\end{array}$ & $\begin{array}{l}\text { - Fresh food raw materials = kesegaran } \\
\text { bahan baku makanan } \\
\text { - Air quality = kualitas udara sekitar } \\
\text { - Energy Efficiency = penghematan } \\
\text { energi } \\
\text { - Water Effeciency = penghematan air }\end{array}$ \\
\hline Kepuasan Konsumen & $\begin{array}{l}\text { Terpenuhinya harapan } \\
\text { konsumen sesuai } \\
\text { kebutuhannya }\end{array}$ & $\begin{array}{l}\text { Kepuasan terhadap kualitas layanan } \\
\text { resto } \\
\text { Kepuasan terhadap produk layanan resto } \\
\text { Kepuasan terhadap lingkungan layanan } \\
\text { resto }\end{array}$ \\
\hline
\end{tabular}


JEMAP: Jurnal Ekonomi, Manajemen, Akuntansi, dan Perpajakan

ISSN: 2622-612X (Media Online) | Vol.4 | No.2 | Oktober 2021

\section{METODE PENELITIAN}

Obyek penelitian dipilih Resto Kampoeng Rawa yang berlokasi di Rawapening Ambawara Kabupaten Semarang. Resto yang terletak di pinggir rawa ini terlihat menjorok ke dalam rawapening dengan pemandangan sekitar air rawa dan alam sekitar yaitu pegunungan. Keindahan alam sekitar dipadukan dengan kuliner menjadi daya tarik resto ini menjadikan alasan dipilih sebagai obyek penelitian ini.

Populasi penelitian ini adalah para konsumen resto Kampoeng Rawa yang menikmati kuliner di lokasi resto. Diambil sampel secara quota accidental sampling karena keterbatasan biaya dan masa pandemi yang membatasi jumlah pengunjung restoran hanya separuh dari kapasitas, dipilih responden yang berkunjung menikmati kuliner dan mempunyai kesediaan mengisi atau menjawab kuesioner yang diedarkan. Besar sample ditentukan sejumlah 60 responden.

Teknik pengumpulan data penelitian menggunakan teknik survey responden dan alat pengumpulan data menggunakan kuesioner. Pengumpulan data dilakukan oleh enumerator yang mengunjungi Resto Kampoeng Rawa. Kuesioner berisi pilihan pertanyaan terkait variabel penelitian yaitu green product, service scape, kualitas layanan dan kepuasan pelanggan dengan skala likert. Penelitian dilakukan selama bulan Februari Maret April 2021 dan dipilih hari survey pada hari Sabtu dan Minggu dimana ada relatif banyak pengunjung yang makan di resto.

Hasil uji validitas indikator variabel penelitian semuanya valid karena di atas r tabel 0,265, dapat dilihat pada tabel sebagai berikut:

Tabel 3 Hasil Uji Validitas

\begin{tabular}{|c|c|c|c|}
\hline Indikator variabel & Nilai r hitung & Nilai r tabel & Keterangan \\
\hline KL11 & 0,322 & 0,265 & Valid \\
\hline KL12 & 0,271 & 0,265 & Valid \\
\hline KL21 & 0,346 & 0,265 & Valid \\
\hline KL22 & 0,524 & 0,265 & Valid \\
\hline KL31 & 0,598 & 0,265 & Valid \\
\hline KL32 & 0,579 & 0,265 & Valid \\
\hline KL41 & 0,537 & 0,265 & Valid \\
\hline KL42 & 0,390 & 0,265 & Valid \\
\hline KL51 & 0,496 & 0,265 & Valid \\
\hline KL52 & 0,613 & 0,265 & Valid \\
\hline SS11 & 0,578 & 0,265 & 0,265 \\
\hline
\end{tabular}


JEMAP: Jurnal Ekonomi, Manajemen, Akuntansi, dan Perpajakan

ISSN: 2622-612X (Media Online) | Vol.4 | No.2 | Oktober 2021

\begin{tabular}{|c|c|c|c|}
\hline Indikator variabel & Nilai r hitung & Nilai r tabel & Keterangan \\
\hline SS21 & 0,706 & 0,265 & Valid \\
\hline SS22 & 0,635 & 0,265 & Valid \\
\hline SS31 & 0,572 & 0,265 & Valid \\
\hline GP1 & 0,491 & 0,265 & Valid \\
\hline GP2 & 0,455 & 0,265 & Valid \\
\hline GP3 & 0,448 & 0,265 & Valid \\
\hline GP4 & 0,558 & 0,265 & Valid \\
\hline KK1 & 0,391 & 0,265 & Valid \\
\hline KK2 & 0,531 & 0,265 & Valid \\
\hline KK3 & 0,515 & 0,265 & Valid \\
\hline KK4 & 0,582 & 0,265 & 0,265 \\
\hline KK5 & 0,521 & & \\
\hline
\end{tabular}

Sumber : Data Primer yang diolah, Juni 2021

Hasil uji reliabilitas variabel penelitian semuanya reliabel karena di atas Cronbach Alpha yaitu 0,7 yang dapat dilihat pada tabel sebagai berikut:

Tabel 4 Hasil Uji Reliabilitas

\begin{tabular}{|c|c|c|c|}
\hline Indikator variabel & $\begin{array}{c}\text { Nilai Cronbach } \\
\text { Alpha hitung }\end{array}$ & $\begin{array}{c}\text { Nilai Cronbach } \\
\text { Alpha Uji }\end{array}$ & Keterangan \\
\hline KL & 0,796 & 0,7 & Valid \\
\hline SS & 0,828 & 0,7 & Valid \\
\hline GP & 0,703 & 0,7 & Valid \\
\hline KK & 0,744 & 0,7 & Valid \\
\hline
\end{tabular}

Sumber : Data Primer yang diolah, Juni 2021

Analisis data penelitian ini menggunakan regresi berganda yang akan menguji pengaruh secara bersama dan secara parsial. Software yang digunakan adalah SPSS versi 22. Hipotesis yang akan dilakukan adalah uji t untuk pengujian pengaruh parsial, dan uji $\mathrm{F}$ untuk pengujian pengaruh bersama. Hipotesis penelitiannya adalah apakah ada pengaruh green product, servicescape dan kualitas layanan terhadap kepuasan konsumen pada Resto Berbasis Alam Sekitar di Kabupaten Semarang. Untuk melihat besar pengaruh, maka akan dilihat koefisien determinan (KD).

\section{HASIL DAN PEMBAHASAN}

Berdasarkan hasil survey ke konsumen yang mendatangi Resto Kampoeng Rawa di Ambarawa, didapat hasil penelitian yang dilaporkan dalam bab ini. Diawali dengan gambaran umum pengelola restoran Kampoeng Rawa dan dilanjutkan dengan gambaran responden penelitian, kemudian hasil analisis regresi yang dilakukan. 
JEMAP: Jurnal Ekonomi, Manajemen, Akuntansi, dan Perpajakan

ISSN: 2622-612X (Media Online) | Vol.4 | No.2 | Oktober 2021

\section{Gambaran Umum Pengelola Resto}

Resto Kampoeng Rawa Ambarawa berlokasi di Jalan Lingkar Ambarawa Km 3 Ambarawa Kabupaten Semarang Jawa Tengah, berdiri sejak Juni 2018 sebagai salah satu unit usaha dibawah BUMDes (Badan Usaha Milik Desa) Bejalen Kecamatan Ambarawa. Pendirian Resto Kampoeng Rawa Ambarawa diprakarsai oleh beberapa kelompok tani yang bercocok tanam disekitar Danau Rawa Pening, dibawah binaan KSP Artha Prima. Tujuan utamanya : untuk menampung, memasarkan hasil perikanan, kerajinan dan semua potensi alam Danau Rawa Pening serta sebagai tempat pembelajaran kepada masyarakat sekitar untuk menjaga pelestarian ekosistem Danau Rawa Pening. Usaha ini merupakan One Village One Product (OVP) Agrowisata perikanan Kampoeng Rawa telah dimasukkan dalam instruksi Gubernur Jawa Tengah No. 518/23546 Tanggal 30 Des 2011 tentang produk unggulan daerah melalui pendekatan One Village One Product (OVP) yang berbasis koperasi di Jawa Tengah dalam hal ini KSP Artha Prima.

Resto Kampoeng Rawa Ambarawa beroperasi setiap hari dari jam 08.00 16.00 WIB, dengan jumlah karyawan 15 orang dan dikelola oleh Bapak Simon sebagai General Manager, Ibu Manager Marketing dan Bapak Rendy Engki sebagai Manager Resto. Adapun bidang usaha yang ditangani Rumah makan lesehan (terletak di Wilayah Kampoeng Rawa sebelah Timur) menyajikan makanan khas Danau Rawa Pening serta makanan khas Indonesia lainnya. Tersedia juga 2 kolam pemancingan dilengkapi dengan alat pancingnya, juga dilengkapi dengan Area Permainan seperti bebek air, flying fox, becak, bendi, mobil wisata, perahu motor dan juga selfie spot, taman bermain keluarga. Tarip masin-masing permainan juga berbeda, berkisar antara Rp 10.000,- hingga Rp 25.000,-. Di lokasi Wilayah Kampoeng Rawa Ambarawa juga tersedia terapi ikan serta craft centre sebagai pusat oleh-oleh khas Jawa Tengah (anyaman enceng gondok, crispy ikan wader, carica, lumpia, tahu bakso). Kampoeng Rawa Ambarawa juga menyediakan 6 fasilitas meeting room dengan tarip berkisar antara Rp 200.000,- sampai dengan Rp 750.000,- (Pendopo “Ageng Dewi Tara”, Hall “Apung Rawa Pening”, Joglo “Alit Kumambang”, Lesehan “Arjuna” \& "Semar”, Lesehan "Rawa Makmur” \& "Rawa 
JEMAP: Jurnal Ekonomi, Manajemen, Akuntansi, dan Perpajakan

ISSN: 2622-612X (Media Online) | Vol.4 | No.2 | Oktober 2021

Asri”, Dinning Room Lesehan), serta fasilitas pendukung lainnya seperti persewaan kursi, meja, sound system dsbnya.

\section{Gambaran Umum Responden}

Responden dalam penelitian ini adalah para konsumen resto Kampoeng Rawa Ambarawa yang menikmati kuliner di lokasi resto sebanyak 60 responden. Hasil penelitian terkait dengan asal kota konsumen yang menjadi responden, sebagian besar 96,6 \% responden berasal dari Pulau Jawa, tetapi ada juga 3,4 \% responden yang berasal dari luar pulau (Kalimantan - Banjarmasin). Bila dilihat dari hasil penelitian, sebagian besar responden $(16,7 \%)$ berasal dari Semarang, berikutnya $(8,3 \%)$ berasal dari Jakarta. Dari seluruh responden yang berjumlah 60 orang, jumlah antara yang berjenis kelamin laki-laki dan perempuan hampir sebanding, ada sebanyak 53,3\% berjenis kelamin laki-laki dan sisanya 46,7\% perempuan.

Kedatangan konsumen pada Resto Kampoeng Rawa Ambarawa biasanya tidak secara individu, tetapi rombongan baik rombongan keluarga, kantor, arisan atau komunitas yang lain. Berdasar hasil penelitian terhadap 60 responden hanya $1,7 \%$ yang datang secara individu, sedang sisanya 98,3\% datang bersama rombongan. Jumlah dalam rombongan yang menjadi konsumen Resto Kampoeng Rawa juga bervariasi, sekitar 4 orang hingga 28 orang konsumen dengan jenis kelamin laki-laki dan perempuan. Banyaknya rombongan yang datang antara yang berjenis kelamin laki-laki dan perempuan berimbang jumlahnya (laki-laki 53,3\% dan perempuan $46,7 \%$ ).

Loyalitas konsumen juga terlihat pada frekuensi kunjungan. Hasil penelitian menunjukkan ada 50\% konsumen yang berkunjung kurang dari 10 kali. Namun demikian ada sejumlah 1,7\% responden yang berkunjung lebih dari 15 kali bahkan juga ada 1,7\% yang berkunjung lebih dari 20 kali. Hal ini menunjukkan bahwa konsumen loyal terhadap terhadap Resto Kampoeng Rawa Ambarawa. Kesetiaan konsumen terhadap terhadap Resto Kampoeng Rawa Ambarawa bila dilihat berdasar jenis kelamin tidak jauh berbeda, namun demikian kalau dilihat dari banyaknya frekuensi berkunjung ke Resto Kampoeng Rawa Ambarawa (lebih dari 10 kali kunjungan), masih didominasi kaun laki-laki (3,4\%). 
JEMAP: Jurnal Ekonomi, Manajemen, Akuntansi, dan Perpajakan

ISSN: 2622-612X (Media Online) | Vol.4 | No.2 | Oktober 2021

Hasil penelitian pada Resto Kampoeng Rawa Ambarawa bila dikaitkan antara asal kota dan jumlah rombongan, menunjukkan bahwa yang membawa rombongan dengan jumlah sekitar 8 orang terbanyak adalah berasal dari kota Demak $(1,7 \%)$. Ada juga rombongan dengan 6 orang berasal dari Semarang, Jakarta, Karanganyar, Pekalongan dengan total $8,3 \%$. Jumlah yang sama $8,3 \%$ terjadi pada rombongan responden dengan jumlah orang yaitu dari kota Ambarawa, Magelang, Temanggung, Yogyakarta. Sedang rombongan konsumen yang menikmati makanan di Resto Kampoeng Rawa Ambarawa sebanyak 3 kali kebanyakan $(28,3 \%)$ datang dari kota Ambarawa, Banjarmasin, Boyolali, Brebes, Cirebon, Kendal, Pati, Semarang, Ungaran, Yogya. Selanjutnya rombongan dengan jumlah 4 orang $(46,7 \%)$ merupakan jumlah rombongan yang paling sering mengunjungi Resto Kampoeng Rawa Ambarawa, berasal dari kota Ambarawa, Bandung, Blora, Boro, Boyolali, Demak, Jakarta, Kendal, Kudus, Magelang, Pati, Pekalongan, Purworejo, Salatiga, Semarang, Tangerang, Tuntang, dan ada pula yang berasal dari Kalimantan. Untuk rombongan dengan jumlah anggota 5 orang ada sekitar 6,7\% berasal dari kota Banyubiru, Jakarta, Pemalang.

\section{ANALISIS REGRESI}

Untuk mengetahui adanya pengaruh green product, servicescape dan kualitas layanan terhadap kepuasan dipakai analisis regresi berganda. Dari pengolahan data SPSS, terlihat hasil korelasi berganda $\mathrm{R}$ adalah 0,715 dengan $\mathrm{R}$ square sebesar 0,511 atau 51,10 persen pengaruh variabel independen terhadap variabel dependen. Hal ini berarti pengaruh green product, servicescape dan kualitas layanan adalah sebesar 51,10 persen terhadap kepuasan konsumen restoran Kampoeng Rawa Ambarawa.

\section{Tabel 5 Model Summary}

\begin{tabular}{|c|c|c|c|c|}
\hline Model & R & R Square & Adjusted R Square & Std. Error of the Estimate \\
\hline 1 & $0,715^{\mathrm{a}}$ & 0,511 & 0,485 & 1,220 \\
\hline
\end{tabular}

a. Predictors: (Constant), TOTAL GP, TOTAL KL, TOTAL SS

Dari tabel Anova terlihat nilai F hitung sebesar 19,499; sedangkan nilai F tabel untuk df1 n-1 dan df2 n-k maka $F$ tabel $(3,56)$ adalah 0,361 . Hal ini menunjukkan bahwa pengaruh semua variabel secara bersama-sama adalah 
JEMAP: Jurnal Ekonomi, Manajemen, Akuntansi, dan Perpajakan

ISSN: 2622-612X (Media Online) | Vol.4 | No.2 | Oktober 2021

signifikan karena $\mathrm{F}$ hitung lebih besar daripada $\mathrm{F}$ tabel atau nilai sig 0,000 di bawah alpha 0,05. Dengan demikian hipotesis bahwa ada pengaruh secara bersama-sama variabel kualitas pelayanan, servicescape dan green product terhadap kepuasan konsumen menjadi terbukti nyata ada pengaruh.

Tabel 6 ANOVA ${ }^{a}$

\begin{tabular}{|c|l|l|l|l|l|c|}
\hline \multicolumn{2}{|c|}{ Model } & \multicolumn{1}{c|}{$\begin{array}{c}\text { Sum of } \\
\text { Squares }\end{array}$} & df & Mean Square & \multicolumn{1}{c|}{ F } & Sig. \\
\hline \multirow{2}{*}{1} & Regression & 87,058 & 3 & 29,019 & 19,499 & $0,000^{\mathrm{b}}$ \\
\cline { 2 - 7 } & Residual & 83,342 & 56 & 1,488 & & \\
\cline { 2 - 7 } & Total & 170,400 & 59 & & & \\
\hline
\end{tabular}

a. Dependent Variable: TOTAL KK

b. Predictors: (Constant), TOTAL GP, TOTAL KL, TOTAL SS

Berdasarkan analisis regresi, terlihat bahwa masing-masing koefisien regresi variabel independen mempunyai pengaruh terhadap variabel dependen. Namun dari uji t, terlihat bahwa hipotesis parsial untuk pengaruh variabel independen adalah berbeda, ada yang signifikan dan ada yang tidak signifikan.

Koefisien regresi variabel kualitas layanan mempunyai koefisien regresi 0,349 atau ada pengaruh positif terhadap kepuasan konsumen. Terlihat nilai t hitung adalah 6,238. Dari t tabel untuk $\mathrm{n}=60, \mathrm{df}=\mathrm{n}-2=58$; terlihat nilai $\mathrm{t}$ tabel adalah 0,265. Karena thitung lebih besar dari t tabel atau signifikansi 0,000 di bawah alfa 0,05, maka dapat disimpulkan bahwa ada pengaruh positif dan signifikan variabel kualitas layanan terhadap kepuasan konsumen restoran kampoeng rawa ambawara. Hipotesis yang menyatakan kualitas layanan berpengaruh positif dan signifikan terhadap kepuasan konsumen dengan demikian terbukti nyata.

Selain itu dari tabel koefisien regresi juga terlihat adanya pengaruh servicescape restoran terhadap kepuasan konsumen restoran. Nilai t hitung sebesar 2,916. Sedangkan nilai t tabel adalah 0,265. Karena nilai t hitung lebih besar dari $t$ tabel atau nilai probabilitas signifikansi t hitung adalah 0,032 di atas t tabel 0,265 atau signifikansi hitung 0,032 di bawah alfa 0,05 maka ada pengaruh positif dan signifikan servicescape terhadap kepuasan konsumen. Hipotesis yang menyatakan servicescape berpengaruh positif dan signifikan terhadap kepuasan konsumen terbukti nyata. 
JEMAP: Jurnal Ekonomi, Manajemen, Akuntansi, dan Perpajakan

ISSN: 2622-612X (Media Online) | Vol.4 | No.2 | Oktober 2021

Dilain pihak pengaruh terkecil terlihat dari koefisien regresi 0,046 dari variabel green product. Nilai t hitungnya sebesar 0,415 dan probabilitas t sebesar 0,680 atau di atas 0,05 . Karena thitung 0,415 lebih besar daripada t tabel 0,265 atau signifikansi hitung 0,680 di atas alfa 0,05 maka dikatakan tidak ada pengaruh variabel green product terhadap kepuasan konsumen resto Kampoeng Rawa Ambarawa. Hipotesis yang menyatakan green product berpengaruh positif dan signifikan terhadap kepuasan konsumen tidak terbukti.

Tabel 7 Coefficients ${ }^{\mathrm{a}}$

\begin{tabular}{|c|c|c|c|c|c|c|}
\hline \multirow{2}{*}{\multicolumn{2}{|c|}{ Model }} & \multicolumn{2}{|c|}{ Unstandardized Coefficients } & \multirow{2}{*}{$\begin{array}{c}\begin{array}{c}\text { Standardized } \\
\text { Coefficients }\end{array} \\
\text { Beta } \\
\end{array}$} & \multirow[t]{2}{*}{$\mathbf{t}$} & \multirow{2}{*}{ Sig. } \\
\hline & & $\mathrm{B}$ & Std. Error & & & \\
\hline \multirow[t]{4}{*}{1} & (Constant) & -.336 & 3.551 & & -.095 & .925 \\
\hline & TOTAL KL & .349 & .056 & .615 & 6.238 & .000 \\
\hline & \begin{tabular}{|l|} 
TOTAL SS \\
\end{tabular} & .221 & .100 & .217 & 2.196 & .032 \\
\hline & \begin{tabular}{|l|} 
TOTAL GP \\
\end{tabular} & .046 & .110 & .039 & .415 & .680 \\
\hline
\end{tabular}

a. Dependent Variable: TOTAL KK

Berdasarkan hasil pengolahan data SPSS, diketahui ada pengaruh positif dan signifikan dari kualitas layanan dan servicescape terhadap kepuasan. Sedangkan green product tidak signifikan pengaruhnya. Berikut uraian pembahasannya.

Kualitas layanan berpengaruh positif sebesar nilai koefisien regresi beta 0,615 dan signifikan 0,000 menunjukkan bahwa dimensi kualitas layanan berupa tangible, emphaty, reliability, responsiveness dan assurance berpengaruh positif terhadap kepuasan konsumen Restoran Kampoeng Rawa Ambarawa. Hasil penelitian ini sejalan dengan hasil penelitian oleh Ransulangi et al (2015) dan Haryanto (2013) yang juga menemukan pengaruh signifikan dari servicescape terhadap konsumen rumah makan di Manado.

Servicescape berpengaruh positif dengan koefisien beta 0,217 dan signifikansi 0,032 berpengaruh positif dan signifikan menunjukkan bahwa konsumen juga memperhatikan berbagai aspek lingkungan sekitar yang menarik dan membuat suasana makan menjadi menyenangkan di restoran tersebut. Hasil ini sejalan dengan penelitian Ransulangi et al (2015) dan Haryanto (2013) yang juga menemukan pengaruh signifikan dari servicescape terhadap konsumen rumah makan Ocean 27 dan Mc.Donald di Manado. Dari aspek ambient condition 
JEMAP: Jurnal Ekonomi, Manajemen, Akuntansi, dan Perpajakan

ISSN: 2622-612X (Media Online) | Vol.4 | No.2 | Oktober 2021

(lingkungan fisik terkait pancaindera), fungsi dan layout spasial (letak meja kursi perabot fasilitas ruangan) serta tanda simbol yang kelihatan berpengaruh terhadap kepuasan konsumen.

Dari analisis regresi, terlihat bahwa variabel green product tidak berpengaruh signifikan. Namun demikian ada koefisien regresi yang positif dari beta 0,039 artinya ada kecenderungan berpengaruh positif walau kecil sekali. Hal ini berarti semakin meningkat green product maka semakin meningkat pula kepuasan, namun tidak terlihat signifikan karena alfa sig 0,680 di atas nilai kritis alfa 0,05. Hal ini menunjukkan bahwa berbagai upaya restoran terkait produk hijau tidak menjadi perhatian konsumen. Temuan ini berbeda dengan hasil penelitian Fatmawati (2015) yang melihat adanya pengaruh green product terhadap keputusan pembelian.

Ada beberapa alasan mengapa green product tidak signifikan pengaruhnya terhadap kepuasan. Hal green product atau produk hijau meliputi kesegaran produk ikan dan sayuran dari desa sekitar, penghematan listrik dan air, atau masalah pencemaran air di sekitar tidak terlihat menjadi perhatian bagi konsumen pengunjung resto. Limbah sampah dimasukkan dalam kotak sehingga tidak terlihat ada kotoran atau sampah makanan, demikian juga lalat atau binatang lainnya tidak terlihat. Situasi seperti seakan dianggap pengunjung sebagai sesuatu yang seharusnya atau necessity. Bukan dianggap kebutuhan (need) dari konsumen pengunjung restoran. Green product ini mungkin kurang menjadi perhatian konsumen. Mereka menganggap kebersihan adalah sudah menjadi standar atau keharusan bagi restoran sehingga tidak signifikan pengaruhnya. Namun secara bersama-sama variabel green product dan kualitas layanan serta service scape mempunyai pengaruh secara bersama-sama dengan besar pengaruh koefisien determinan sebesar 51,80 persen.

Adanya pengaruh lain terhadap kepuasan konsumen resto sebesar 48,20 persen bisa berupa unsur marketing mix yang lain seperti adanya promosi yang gencar dari pihak kawasan Kampoeng Rawa dan pemerintah daerah sekitar tentang wisata Kampoeng Rawa. Selain itu juga letak atau lokasi restoran Kampoeng Rawa yang strategis sehingga mudah dijangkau konsumen di pinggir jalan lingkar luar kota Ambarawa. Kemudian juga harga makanan di restoran yang terjangkau oleh 
JEMAP: Jurnal Ekonomi, Manajemen, Akuntansi, dan Perpajakan

ISSN: 2622-612X (Media Online) | Vol.4 | No.2 | Oktober 2021

konsumen. Didukung oleh orang-orang atau pengelola yang ramah dan penuh perhatian serta proses penyiapan makanan untuk restoran yang bagus membuat restoran Kampoeng Rawa menjadi pilihan konsumen dan mendukung kepuasan konsumen. Hal ini membuat restoran Kampoeng Rawa juga menjadi tujuan konsumen yang membutuhkan kesegaran suasana atau variasi suasana makan yang berbasis alam sekitar walaupun tidak menjadi variabel penelitian ini.

\section{PENUTUP}

\section{Kesimpulan}

Pengelola Kampoeng Rawa Resto di Ambarawa ini adalah BUMDES bekerja sama dengan swasta yang berpengalaman dalam pengelolaan restoran apung. Karyawan restoran berasal dari penduduk dari tiga desa sekitar. Namun manajer restoran berasal dari profesional.

Konsumen Kampoeng Rawa Resto Ambarawa berasal dari berbagai kota di Indonesia, antara lain dari sekitar Ambarawa, Semarang, Ungaran, Jakarta, Boyolali, Salatiga dan lainnya, bahkan ada yang dari luar pulau Jawa yaitu dari pulau Kalimantan. Pengeluaran mereka di restoran rata-rata sekitar Rp.250.000,00. Mereka datang secara rombongan atau tidak sendirian, bisa dengan keluarga dan teman-temannya. Para responden ini memesan menu yang beragam namun secara umum ada menu ikan dalam pesanannya.

Hasil penelitian menunjukkan bahwa ada pengaruh positif dan signifikan dari variabel kualitas layanan dan servicescape terhadap kepuasan konsumen. Koefisien regresi kualitas layanan terbesar dibanding servicescape dan green product menunjukkan kualitas layanan lebih besar berpengaruh terhadap kepuasan konsumen. Selain itu keadaan suasana sekitar yang berpengaruh positif dan signifikan berarti bahwa kepuasan konsumen juga dipengaruhi oleh servicescape restoran. Green product tidak berpengaruh signifikan karena konsumen tidak begitu memperhatikan aspek produk hijau ini yang dianggap sudah sewajarnya kesegaran ikan dan sayuran serta tidak terlihatnya aspek hijau dalam keterangan atau brosur sehingga konsumen tidak menyadarinya. 
JEMAP: Jurnal Ekonomi, Manajemen, Akuntansi, dan Perpajakan

ISSN: 2622-612X (Media Online) | Vol.4 | No.2 | Oktober 2021

\section{Saran}

Berdasarkan temuan adanya pengaruh positif dan signifikan dari variabel kualitas layanan dan servicescape, maka aspek ini perlu tetap dipertahankan dan dijaga oleh Restoran Kampoeng Rawa. Beberapa cara adalah dengan menyediakan kertas dan kotak saran, atau google form yang dapat diakses konsumen untuk evaluasi layanan dan suasana sekitar restoran. Para karyawan dilatih, praktek memperhatikan pengunjung, trampil melayani dan mendapatkan perhatian untuk selalu peka terhadap konsumen yang menunggu atau belum dilayani. Ada karyawan yang ditugasi mengkoordinir teman-temannya agar memperhatikan tamu dengan teliti dan seksama. Manajemen urutan pesanan dan penghantaran perlu dijaga terus agar konsumen puas atau tidak ada konsumen yang tidak terperhatikan.

Green product tidak berpengaruh karena konsumen tidak menyadari atau tidak paham akan produk hijau tersebut. Apabila restoran ingin menampilkan produk hijau sebagai salah satu daya tarik, maka perlu disebutkan dalam tawaran menu bahwa produk food and beverage mereka adalah produk yang bebas pestisida atau produk organik dan sebagainya yang sesuai kriteria green product.

\section{DAFTAR PUSTAKA}

Anggraini, Atalya (2016). 7 Tips memulai restoran dengan konsep go green, March 6 2016. https://www.nibble.id/blog/7-tips-memulai-restorankonsep-go-green/

Bitner, Mary Jo. (1992). Servicescapes: The impact of physical surroundings on customers and employees. Journal of Marketing. Vol 56. April 1992. P.57-71.

Chase, Richard B., Nicholas J. Aquilano and F. Robert Jacobs, (2002). Operations management for competitive advantage. Ninth Edition. International Edition. New York: McGraw-Hill Higher Education.

D'Souza, C., Taghian, M., Lamb, P., and Peretiatkos, R., (2006). "Green Products and Corporate Strategy: An Empirical Investigation". Society and Business Review. Vol. 1 Iss: 2. 
JEMAP: Jurnal Ekonomi, Manajemen, Akuntansi, dan Perpajakan

Fatmawati, Azizah (2015). Faktor-Faktor yang Mempengaruhi Keputusan Pembelian Green Product. Skripsi. Fakultas Ekonomi dan Bisnis. Universitas Muhannadiyah Surakarta.

Handayani, Novita Tri.,(2012). Pengaruh atribut produk terhadap loyalitas pelanggan green product sepeda motor honda injection. Management Analysis Journal. Volume 1; Nomor 2. Hlm. 1-2.

Harum, M. Huasein, (1993). Lingkungan Hidup: Masalah Pengelolaan dan Penegakan Hukumnya, Jakarta: PT. Bumi Aksara.

Haryanto, Resti Avita, (2013). Strategi promosi, kualitas produk dan kualitas layanan terhadap kepuasan pelanggan mcdonald's manado. Jurnal $E M B A$. Vol 1. No 4. Desember 2013, Hal. 1465-1473

Hidayat, Deby Wahyu; dan Andreas Pandu Setiawan, (2015). Perancangan interior café dan restoran khas surabaya di jalan embong Malang Surabaya. Jurnal Intra Vol 3. No.2 hlm 92-101.

Kasali, Rhenald. (2005). Sembilan Fenomena Bisnis. Jakarta: Gramedia.

Kotler, Philip dan Kevin Lane Keller, (2012). Marketing Management. 14 Edition. Global Edition. Boston: Pearson Education Limited.

Makower, J., Elkington, J., Hailes, J.(1993). The di Green Consumer. USA: Penguin Group.

Nugrahadi, Eko Wahyudi. (2002). Pertanian Organik Sebagai Alternatif Teknologi dalam Upaya Menghasilkan Produk Hijau. Makalah Falsafah Sains (PPs 702) Program Pasca Sarjana IPB. http://www.deptan.go.id (diakses 2 Oktober 2014 pukul 10.32 WIB).

Ottman, J. A., Reilly, W. R. (1998). Green marketing; Opportunity for innovation. Second edition. New Jersey: Prentice Hall.

Parish, Janet Turner, Leonard L. Berry and Shun Yin Lam, (2008). The effect of the service scape on service workers. Journal of Service Research, Vol 10. No.3. February 2008. P.220-238.

Purnama, Rizky Ardi, dan Erna Andajani. (2019). Pengaruh service scape terhadap customer loyalty restoran limited service McDonald's Surabaya. Jakarta: UPN Veteran.

Rath, Ramesh Chandra, (2013). An Impact of Green Marketing on Practices of Supply Chain Management in Asia: Emerging Economic Opportunities 
JEMAP: Jurnal Ekonomi, Manajemen, Akuntansi, dan Perpajakan

ISSN: 2622-612X (Media Online) | Vol.4 | No.2 | Oktober 2021

and Challenges. International Journal of Supply Chain Management Volume 2; Nomor 1.

Ransulangi, Mega Silvia; Silvya Mandey, dan Willem A Tumbuan (2015). Pengaruh kualitas produk, harga dan servicescape terhadap kepuasan konsumen pengguna rumah makan ocean 27 Manado. Jurnal EMBA. No.3. Vol 3. Hal.839-848. September 2015.

Sasongko, Felita dan Hartono Subagio, (2013). Pengaruh kualitas layanan terhadap kepuasan pelanggan ayam penyet ria. Jurnal Manajemen Pemasaran Petra. Vol.1. No.2. 1-7. Surabaya: UK Petra.

Supardi, Bahrudin (2009). Berbakti Untuk Bumi. Bandung: Rosdakarya. 